\title{
RESUMO
}

V.8 $\cdot$ N.1 $\cdot$ Agosto/Setembro/Outubro - 2019

ISSN Digital: 2316-3828

ISSN Impresso: 2316-333X

DOI: 10.17564/2316-3828.2019v8n1p131-140

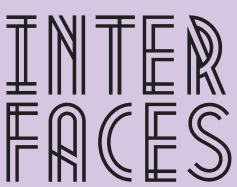

CIENTÍFICAS

\section{SEIS HIPÓTESES CONFIGURADORAS DE CLÁUSULAS DE BARREIRA PARA A EFETIVIDADE NO PROCESSO DE ENSINAGEM JURÍDICA NO BRASIL}

\author{
SEIS HIPÓTESIS QUE CONFIGURAN CLÁUSULAS DE \\ BARRERA PARA LA EFECTIVIDAD DEL PROCESO LEGAL \\ DE ENSEÑANZA JURIIICA EN BRASIL
}

Valtecino Eufrásio Leal ${ }^{1}$ Paulo Alberto da Silva Sales ${ }^{2}$ Geruza Silva de Oliveira Vieira ${ }^{3}$ Marilda Ferreira Machado Leal ${ }^{4}$
A partir da análise do quantitativo de cursos jurídicos existentes no Brasil, procura-se por meio desta pesquisa, teorizar sobre seis hipóteses demonstrativas da inviabilidade de bons resultados nos cursos jurídicos do país. A primeira delas passa pelo alto número de cursos autorizados e reconhecidos. A segunda, é inerente ao empirismo e ao tecnicismo adotados pelos docentes em sala de aula. A terceira versa sobre o conflito de linguagem e de comunicação entre as duas gerações que dificulta o processo de ensino-aprendizagem. A quarta tem como foco a relação ou o vínculo de trabalho dos professores com as instituições, que em larga escala, são agentes públicos ou profissionais autônomos, que adotam a docência como segunda profissão ou complemento de renda. A quinta questiona o fato do MEC realizar visitas e inspeções às instituições e aos cursos jurídicos, apenas trienalmente e a última, relaciona-se com a oferta de cursos, apenas em turnos noturnos. 0 objetivo da investigação é proporcionar diálogos acadêmicos que venham ampliar-se em favor de melhoras no ensino jurídico.

\section{PALAVRAS-CHAVE}

Ensino Jurídico. Estratégias. Efetividade. Dignidade Humana. Conflito de Gerações. 


\section{ABSTRACT}

Based on the analysis of the quantitative of Law Courses in Brazil, this research seeks to theorize about six hypotheses demonstrating the impracticability of good results in the legal courses of the country. The first of these passes through the high number of authorized and recognized courses. The second is inherent to the empiricism and technicality adopted by teachers in the classroom. The third is about the conflict of language and communication between the two generations that hampers the teaching-learning process. The fourth focuses on the relationship or the working relationship of teachers with institutions, which are large-scale public agents or autonomous professionals, who adopt teaching as a second profession or income supplement. The fifth questioned the fact that the MEC visits and inspects institutions and legal courses only triennially and the last, is related to the offer of courses, only in night shifts. The aim of the research is to provide academic dialogues that will expand in favor of improvements in legal education.

\section{KEYWORDS}

Legal education. Strategies. Effectiveness. Human dignity. Conflict of generations.

\section{RESUMEN}

Sobre la base del análisis de los cursos cuantitativos de derecho en Brasil, esta investigación busca teorizar sobre seis hipótesis que demuestran la impracticabilidad de los buenos resultados en los cursos jurídicos del país. El primero de estos pasa por la gran cantidad de cursos autorizados y reconocidos. El segundo es inherente al empirismo y la tecnicidad adoptada por los maestros en el aula. El tercero trata sobre el conflicto de lenguaje y comunicación entre las dos generaciones que dificulta el proceso de enseñanza-aprendizaje. El cuarto se centra en la relación laboral de los docentes con las instituciones, que son agentes públicos a gran escala o profesionales autónomos, que adoptan la enseñanza como una segunda profesión o complemento de ingresos. El quinto cuestionó el hecho de que el MEC visite e inspeccione instituciones y cursos legales solo trienalmente, y el último está relacionado con la oferta de cursos, solo en turnos nocturnos. El objetivo de la investigación es proporcionar diálogos académicos que se expandan a favor de mejoras en la enseñanza jurídica.

\section{PALABRAS CLAVE}

Enseñanza jurídica. Estrategias. Eficacia. Dignidad humana. Conflicto de generaciones. 


\section{INTRODUÇãO}

Neste ensaio, pretende-se demonstrar algumas hipóteses configuradoras de cláusulas de barreira para a efetividade do processo de formação jurídica no Brasil. Nessa argumentação semântica, são apresentados como objetivo de fundo, questionamentos referentes à estrutura desse curso no país e suas possibilidades de provocar colapso na apropriação do conhecimento e saturação do mercado profissional, por ocasião do ingresso dos bacharéis em Direito que colam grau a cada semestre.

A problemática, conquanto não seja recente, envolve repensares para além das ideias e crenças predominantes, ou, sobre a ontologia jurídica do conhecimento dogmatizado a partir da exegese legal. Há também que se alertar para a ausência de estudos acadêmicos mais pujantes que ampliem o debate sobre esse conformismo cognitivo preocupante, em meio ao modelo formal de educação jurídica desse ponto de incertezas e do desconhecido, perante uma lógica de resistência mercantilizada e algumas realidades paradoxais cientificamente, desse contexto pluralizado que está a desafiar transformações.

Nesse plexo de incertezas, tematizar sobre o processo de ensino-aprendizagem e a educação jurídica no Brasil, é deparar com um enorme quantitativo de instituições públicas e privadas que procuram adequar-se aos padrões de exigência para o ensino, refletidos por acadêmicos e suas avaliações sazonais, a serviço do Ministério da Educação e Cultura, mas, ao mesmo tempo, é enxergar um sistema precário no aspecto didático-pedagógico que veio se ampliando sem controle ao longo dos anos e agora, de algum modo, está a exigir urgente reestruturação. Porquanto, não se pode perder de vista, nesse olhar de preocupação, a verdadeira questão de fundo, alinhada à enorme multidão de bacharéis em Direito que a cada ano, encerra o ciclo do ensino superior e que em tese, estaria apta a ingressar no acirrado mercado de atuação jurídica.

Enviesar a discussão ambivalente entre a qualidade do ensino jurídico e o pragmatismo da formação desses milhares de jovens, talvez não ofereça uma resposta fidedigna à problemática que se propõe, mas algumas indagações devem merecer especial preocupação de todos os profissionais da educação jurídica, especialmente em razão de resultados niilistas em pontos de reflexões de quem se prestar a avaliar dados, números estatísticos e as possibilidades do mercado de trabalho para esse campo do saber.

Nesta pesquisa, adverte-se, não há o escopo propriamente de se investigar a fundo a origem do problema e nem existe a pretensão de se apontar sugestões programáticas representativas de rumos imediatos ou de mudanças. Entretanto, são apresentadas algumas hipóteses compreendidas como relevantes, delineadoras de um ineditismo vertente sobre um apagão para a situação e seus resultados imprevisíveis, numa realidade que ampliou-se por alguns anos e que deve marcar um ponto de reflexão para embates acadêmicos necessários e inevitáveis a curto prazo, perante essa névoa de mutação em curso nessa área da educação.

Assim, ao amparo de reflexões de alguns pensadores da área e da educação superior, procura-se expor, a partir das questões postas, um plano de ideias que possa prestar-se a pensares no plano profissional individual e coletivo, em razão das urgências recorrentes no processo de ensinagem, que formata a violação da dignidade humana numa lógica de ensino massificado e mercantilizado. Nesse aspecto, jovens acadêmicos, em centenas de curso de direito, a cada ano, enxergam e apostam 
em boas realizações no amanhã, com a formação e após a colação de grau, deparam-se com muitas dificuldades e até com a impossibilidade de ingresso numa profissão jurídica.

\section{SEIS HIPÓTESES A IMPACTAR O PROCESSO DE FORMAÇ̃̃O JURÍDICA, FAVORÁVEIS À EXCLUSÃO E VIOLAÇÃO INDIRETA DA DIGNIDADE HUMANA}

O ensino superior, em nações em desenvolvimento, é um dos principais meios de inclusão e de outorga da dignidade humana. No entanto, as bases epistemológicas padronizadas e afetas à transmissão de habilidades e competências empiristas, estão a cercear, no campo do direito, o pensar, o repensar e as interconexões ou a indissociabilidade entre o aprender, a teoria e o fazer ou a prática.

Essa linha de cisão entre teoria e prática, tem levado os profissionais que lidam diretamente com o ensino jurídico no Brasil, em instituições públicas e privadas, não raramente a preocupações com a qualidade dos cursos jurídicos em quais atuam. Como fator complicador desse antagonismo, muitos gestores ocupam-se e preocupam-se com o rigor acadêmico dos profissionais do Ministério da Educação e Cultura - mais do que exigível - que no país, a cada três anos, efetuam visitas e avaliações de cursos que tendem a ranqueamentos de qualidade do ensino superior. Há também o receio expresso ou oculto, da perda de vagas, por evasão de alunos, o que pode refletir na perda de emprego e até no fechamento de cursos, por má qualidade nos processos de formação.

Por razões como essas, algumas instituições e seus colaboradores, procuram se antecipar aos cortes de vagas que mais cedo ou mais tarde existirão, numa corrida contra o tempo, na reestruturação de projetos políticos pedagógicos, que signifiquem higidez, interdisciplinaridade, matriz curricular transversal e dinâmicas de aprendizagens adequadas. Essa luta, contudo, nem sempre é tão pujante e há inércia e omissão por parte daqueles empreendedores do ensino que priorizam o lucro predatório e com isso, conduzem egressos e bacharéis em Direito, em sua maioria, a resultados pífios, com baixos índices de aproveitamento em exames e concursos, fator este que pressupõe um hiato entre a formação jurídica e a aptidão para o exercício de habilidades e competências assimiladas ao longo de cinco anos pelo bacharel.

No transcorrer de algumas décadas, muitos pensadores como Barreto Filho (1967), Santos (1994), Bachelard (2000) e Anastasiou e Alves (2009), em repúdio às práticas de muitas instituições brasileiras, têm se desdobrado em debates e na busca de estratégias docentes inovadoras que signifiquem melhoras na apropriação do conhecimento por acadêmicos, a partir de uma cosmovisão do ensino não redutivo como o cartesiano - ainda prevalecente em muitos cursos jurídicos - e que impliquem numa verdadeira reforma do processo de ensinagem.

Nesse contexto, a fim de ponderar e refletir sobre a formação jurídica de algumas faculdades, centros universitários e universidades brasileiras, serão apresentadas em seguida, seis hipóteses aqui compreendidas como impactantes nos prognósticos e resultados da má formação jurídica nas centenas de instituições de ensino do Brasil.

A primeira dessas questões, aqui enxergada como principal, reside no número alarmante de cursos jurídicos reconhecidos pelo Ministério da Educação - em 2011, existiam 1.178 cursos reconhe- 
cidos. Há quem argumente que esse número chegou a $1.210^{5}$, mas oficialmente, no fechamento do ano de 2016, havia registros no endereço eletrônico do MEC de 1.266 cursos em funcionamento. Portanto, além da verdadeira preocupação com o ensino de qualidade, ainda prevalece uma disputa mercadológica por acadêmicos, especialmente em instituições de ensino privado e essa mercantilização, tende a resultar numa formação de baixa qualidade, por facilitação no processo de transmissão do saber e até em avaliações, por receio da evasão de discentes.

Sobre os números em questão, é bom lembrar que os EUA possuem população superior à brasileira em mais de cinquenta por cento e por lá existem cerca de 212 cursos de Direito ${ }^{6}$. Mais do que isso, segundo o então presidente da Ordem dos Advogados do Brasil, Marcus Vinícius Coelho, o curso de Direito se banalizou e em sua retórica, o Brasil, quantitativamente, possuiria mais faculdades e vagas nessa área do saber do que todos os países do mundo ${ }^{7}$, conjuntamente.

A segunda questão que se apresenta e se discute, enviesa por fatores que impactam de modo direto o padrão didático-pedagógico, ou as ações docentes, aqui articuladas como a mesmice, a resistência ao novo e o empirismo aliado à exegese legal, ainda praticado em sala de aula. Nessa vertente, a maioria dos professores brasileiros, embora alertados quotidianamente, ainda não se deram conta de que as velhas práticas tecnicistas, atreladas às experiências profissionais e ao modelo cartesiano, conquanto mais pujantes/atrativas para retóricas e embates, não mais se sustentam e levam à ineficácia na atividade científica.

Esse modelo de gavetas ou compartimentalização de conteúdos, em qual cada disciplina é ministrada de modo isolado e sem verticalizações ou horizontalizações, passa por releituras em algumas instituições de ensino, a partir de reflexões como a de Anastasiou (2009) e Bachelard (2001). Todavia, essas discussões ainda são eminentemente teóricas e o processo de mudança, enfrenta resistências para superação do dogmatismo sistêmico, alinhado às verdades quase absolutas de que disciplinas básicas não se confundem com outras fundamentais ou práticas. Esse padrão de comportamento é repudiado por Morin (2005, p. 24), ao refletir que “[...] a ciência não é somente a acumulação de verdades verdadeiras".

0 terceiro ponto, não menos relevante, cinge-se ao acesso às novas tecnologias e aos modos de comunicação inteligente da chamada geração z, que engloba pessoas hiperconectadas ou nativas digitais, nascidas a partir do ano de 1990. Esse grupo representa a massiva maioria dos acadêmicos atuais presentes em sala de aula e os professores, em grande parte, com as vivências e experiências profissionais adquiridas em padrão ideologizado por gerações anteriores, deparam-se com um conflito emergente e relevante na comunicação. Por isso, por mais que o esforço seja hercúleo, o encontro dessas gerações tende a protagonizar técnicas de ensino despiciendas para o público discente.

5 Listagem dos cursos reconhecidos, com esse número, disponível no Jornal O Estado de São Paulo. Edição de 23 nov. 2011. 6 Conforme opinião de Helio Duque (2016, p. 2), “[] nos Estados Unidos, existem 212 faculdades de Direito. Nos próximos dez anos, 15 delas vão fechar as suas portas, tendo começado pela Faculdade de Direito de Vermont. Ao final do processo sobrarão 197 escolas. A razão é objetiva: a Ordem dos Advogados dos EUA constatou que $55 \%$ dos bacharéis, formados em 2011, não encontraram emprego na área do Direito. [...]"

7 Ver matéria no site: http://www.oab.org.br/noticia/20734/brasil-sozinho-tem-mais-faculdades-de-direito-que-todos-os-paises. Acesso em: 22 maio 2016. 
Como quarto argumento, os cursos jurídicos proporcionam formação e abrem oportunidades para várias profissões, e, perante a acirrada disputa no mercado de trabalho, muitos bacharéis ingressam no magistério universitário com a finalidade de complementar renda. Alguns desses professores, são magistrados, promotores, advogados, procuradores e outros. Tais profissionais, com raríssimas exceções, praticam a docência ou para auferir ganho extra, ou porque desejam realizar algum "sonho oculto" e não demonstram o comprometimento necessário à profissão adotada em plano secundário.

0 quinto ponto a considerar diz respeito ao fato de algumas instituições de ensino também colaborarem de modo intenso para a má qualidade na formação, sem disponibilização de recursos suficientes e investimentos adequados para o curso jurídico. Geralmente, reservam valores para algumas melhoras, somente por ocasião de visitas rotineiras por profissionais avaliadores designados pelo MEC, o que ocorre em ciclos periódicos de três anos. Por esses motivos, algumas dimensões como a pesquisa, a extensão, a necessidade de professores com tempo parcial e integral, as boas instalações, a biblioteca atualizada e outras particularidades estruturais e pedagógicas, relegadas a planos sazonais, impactam na desmotivação e na ausência de profissionalização da docência.

A sexta questão refere-se à oferta, em grande parte, de cursos jurídicos com matrizes em apenas um turno, geralmente no horário noturno, o que proporciona um público de trabalhadores que mescla oito horas de trabalho diário com quatro horas de estudo noturno. Essa situação vai na contramão do ensino praticado por instituições europeias e norte-americanas, onde, conforme aponta Barreto Filho (1967, p. 357), a maioria das boas instituições “[...] adotam programas de estudo com tempo integral, tanto no que se refere a professores, como a estudantes".

Nesse aspecto, o que já existia nos EUA na década de sessenta, a partir das pesquisas de Barreto Filho (1967), como a flexibilização curricular e professores a tempo parcial e integral, somente agora nas duas primeiras décadas do Século XXI, começa, tardiamente, a ganhar alento no Brasil.

Os males e as encruzilhadas têm diversas faces e talvez a mais proeminente seja a globalização e o avançar da dinâmica de mercado econômico que no Brasil, transformou o ensino superior num mercado de larga amplitude e a era neoliberal, com seu rastros inapagáveis, secundarizou a preocupação das sociedades com as políticas públicas protecionistas da cientificidade. Por isso, a exploração comercial de alguns nichos, como o direito, a medicina e outras áreas, prioriza a massificação e os lucros, palpáveis nas consequências que nos dias presentes começam a produzir efeitos deletérios.

\section{PARA ALÉM DA RUPTURA DO ENSINO ESTANDARTIZADO}

As reflexões sobre os seis pontos apresentados acima, aproximam-nos das urgências recorrentes no ensino jurídico e além de configurarem cláusulas de barreira para a efetividade nos cursos de direito, são causas e efeitos de quais os professores também situam-se como os principais protagonistas. Aos docentes comprometidos com o pragmatismo da teoria e da prática, cabem indagar e procurar respostas que contribuam em favor de uma virada no processo ou até em caráter de autoajuda, com vistas à busca de luzes que venham mitigar o obscurantismo das perspectivas desse devir. 
As insurgências em questão estão a exigir reestruturações, mudanças comportamentais e mais especificadamente, a compreensão de que a ordem de um todo passa pelas singularidades e se cada corresponsável colaborou direta ou indiretamente para o caos, talvez seja hora de mudar o curso do leme, para dar razão a Bachelard (2000, p. 168) e sua afirmação de que: "muitas vezes me tenho impressionado com o fato de os professores de ciências, mais ainda, se possível, do que os outros, não compreenderem que não se compreenda."

Bachelard (2000, p. 168) aponta como tarefa do professor derrubar obstáculos e ainda “[...] propiciar rupturas com o senso comum, com um saber que se institui da opinião e com a tradição empiricista das impressões primeiras". Desse modo, embora existam particularidades nos seis argumentos apresentados acima que não dependem diretamente do educador, não mais se pode imaginar no sucesso de modelos de aulas ou de ensino estranhos ou fora do contexto dos acadêmicos nativos digitais.

Na opinião crítica de Bachelard é preciso criar dificuldades para nós próprios, é necessário que existam esses problemas heterogêneos, sem respostas prontas, pois somente assim, o espírito científico romperá com valores e culturas. Por isso, os professores do ensino jurídico não devem se esquecer que o bom educador, como também visto em Morin (2005, p. 26) deve articular-se com a autocrítica e impor a si mesmo, "a contestação das suas próprias estruturas de pensamento".

É preciso também, a partir de Morin, mudar a visão de mundo, crer em revoluções, ou pensar antropologicamente, para, na condição de portadores de uma determinada cultura, auto-relativizar a condição de mero observador e questionar sobre quem somos e com o que desejamos contribuir em favor das comunidades e das pessoas com as quais convivemos. É necessário uma reelaboração de pensares, num mundo veloz que não mais se sustenta com os exemplos forenses. É essencial “[...] insistir fortemente na utilidade de um conhecimento que possa servir à reflexão, meditação, discussão, incorporação por todos, cada um no seu saber, na sua experiência, na sua vida” (MORIN, 2005, p. 26).

\section{REFLEXÕES FINAIS}

Na linha das reflexões apresentadas empiricamente, é preciso que aceitemos rupturas. 0 docente desse Século XXI, não pode permanecer prisioneiro de uma caverna com grilhões insuperáveis, como advertido por Platão (2001, p. 15):, é responsabilidade do professor mostrar ao aluno que "[...] a capacidade de pensar pertence muito provavelmente a algo de mais divino, que nunca perde a sua força e que, segundo a direção que se lhe imprime, se torna útil e vantajoso ou inútil e prejudicial”.

Se estamos neste mundo acelerado, em que a experiência profissional é substituída por outras ideias e olhares das pessoas que veem e praticam o novo e se a globalização e as inovações tecnológicas, superam velhos clichês e estandartes, também o docente deve compreender e assimilar que a efeméride de realizações passadas, não mais se coaduna com a linguagem e as percepções do público jovem deste Século XXI.

Não se nega que é urgente uma reforma sólida e com respostas a curto prazo, para o sistema de ensino jurídico no Brasil e algumas ações estão a depender de boas instituições e agentes políticos, 
mas não há como fugir da realidade de que o número de cursos de direito no país, extrapolou os limites do razoável. Não mais é plausível pensar em um milhão de advogados no país, um para cada grupo de 200 habitantes e noutros milhões de bacharéis, lutando pela inserção no mercado de trabalho, em disputas plenamente irrazoáveis. Se não há lugar ou profissão para tantos bachareis, qual a razão da autorização estatal para tantos cursos?

Os professores também devem submeter-se a pensares reflexivos. Fugir da realidade e ficar num lugar empirista do passado, com retóricas e exposições ultrapassadas, é esquecer que de algum modo, viajamos numa nave para outra dimensão, onde a internet, as redes sociais, os smartfones e outras criações da computação, representam outra realidade. Porquanto, esses jovens das conexões céleres, dependem do contato direto com essas tecnologias e não há como excluir a linguagem da velocidade da informação, em sala de aula.

Há também um conflito de gerações que não mais pode ser ignorado. É chegada a hora de se pensar na docência como vocação, mediante enxugamento do quadro de professores de alguns cursos jurídicos, para com isso, se propiciar a ampliação de nomes verdadeiramente comprometidos com a docência. Os remanescentes devem priorizar a profissão e assimilar ou renunciar à resiliência de negação dos múltiplos fatores que tornaram o discente, no humano que espera assistir uma interconexão de informações e que não se contenta tão somente com aquelas aulas expositivas estandardizadas ou com metodologias excludentes da interatividade em sala.

Os governantes e a sociedade civil organizada, devem trabalhar conjuntamente para que, no sistema de ensino, notoriamente o remunerado, as instituições superem as tendências de mercantilização da educação. As visitas de docentes nomeados pelo MEC, talvez sejam fatores infirmadores da necessidade de maior fiscalização. A ideia de visitas a cada triênio, no entanto, deve ser repensada. É oportuno que o governo federal amplie essa oportunidade de fiscalização, inclusive eletronicamente, em razão do impacto e da sensível melhora da infraestrutura e do quadro docente das Instituições, nesses salutares momentos de acerto de contas com o MEC.

Nesse contexto, os investimentos de grupos empresariais seriam continuados e melhores resultados existiriam no ensino superior. Outro fator relevante, no caso de visitas anuais, seria a impossibilidade de maquiamento da qualidade e das condições gerais de cada curso.

Finalmente, quanto ao acadêmico trabalhador, os resultados para o direito, no geral, são insatisfatórios, especialmente em razão dos cursos jurídicos dependerem, na atualidade, de muita leitu$\mathrm{ra}$, inclusive em caráter interdisciplinar. Na realidade, os cursos com maior comprometimento, em momentos mais avançados, mesclam aulas em horários noturnos e diurnos, principalmente com a intenção de proporcionar aulas práticas aos alunos.

A tendência natural, nesses cursos de melhor avaliação, a partir de rápida análise e discussão das seis hipóteses acima apresentadas, seria ampliar as aulas dos cursos de direito para horários semi-integrais, com atividades obrigatórias em dois turnos. Nesse ponto, adverte-se, o aluno trabalhador teria prejuízos, mas a opinião, neste artigo, volta-se, exclusivamente, para o critério de qualidade e eficácia do ensino. Aliás, a partir de fomentos, por parte de governos federal e estaduais e das próprias instituições filantrópicas, mediante a redução gradual das vagas ofertadas, os trabalhadores teriam oportunidades de estudo, mediante auxílio governamental ou de filantropia. 


\section{REFERÊNCIAS}

ANASTASIOU, Léa das Graças Camargos; ALVES, Leonir Passate (Orgs.). Estratégias de ensinagem. In: ANASTASIOU, Léa das Graças Camargos; ALVES, Leonir Passate (Orgs.). Processos de ensinagem na universidade: pressupostos para as estratégias de trabalho em aula. 5. ed. Joinvile: 2009.

BACHELARD, Gastón. A epistemologia. Lisboa: Edições 70, 2000.

BACHELARD, Gastón. 0 novo espírito científico. Rio de Janeiro: Tempo brasileiro, 2001.

BARRETO FILHO, Oscar. Novos métodos no ensino do direito: a experiência americana. Revista da Faculdade de Direito, Universidade de São Paulo, [S.I.], v. 63, p. 355-378, dez. 1967. ISSN 23188235. Disponível em: http://www.revistas.usp.br/rfdusp/article/view/66567/69177>. Acesso em: 21 maio 2016.

BARRETO FILHO, Oscar. Novos métodos no ensino do direito: a experiência americana. Revista Forense, Rio de Janeiro: Forense, 1970

BRASIL sozinho tem mais faculdades de direito que todos os países. Disponível em: http://www.oab. org.br/noticia/20734/brasil-sozinho-tem-mais-faculdades-de-direito-que-todos-os-paises.

Acesso em: 20 nov. 2016.

DUQUE, Helio. A inflação dos cursos de direito. Jornal do Comércio Hauer, Ano 10, ed. 171, p. 2. Curitiba, jul.2016.

MELO FILHO, Professor da UFC. Disponível em: http://www.direito.ufc.br/index.php?option=com _content\& task= view\&id=143\&ltemid=67. Acesso em: 21 maio 2016.

MORIN, Edgar. Ciência com consciência. Trad. Maria D. Alexandre e Maria Alice Sampaio Dória. 8. ed. Rio de Janeiro: Bertrand Brasil, 2005.

MEC vai inspecionar 70 instituições mal avaliadas. 0 Estado de São Paulo, p. 20. edição de 23 de novembro de 2011.

PLATÃO. A República. Trad. de Pietro Nassetti. São Paulo: Martin Claret, 2001.

Recebido em: 01 de junho de 2017

Aprovado em: 23 de abril de 201 
1 Doutor em Direito Pela Fadisp; Servidor Público Federal; Professor; Pesquisador. E-mail: altecino@gmail.com

2 Doutor em Letras e Linguística pela UFG; Professor; Pesquisador. E-mail pasticheculture@gmail.com

3 Doutora em Sociologia pela UFG; Professora; Pesquisadora. E-mail: gsocienciasociais@gmail.com

4 Especialista em Direito Público; Professora de Direito do Trabalho; Pesquisadora. E-mail: marilda.leal@uol.com.br

\section{可回 yxis

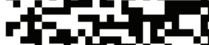

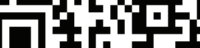

A autenticidade desse artigo pode ser conferida no site https://periodicos set.edu.br

\section{Como citar este artigo:}

ROMEO, Andrea. Lo special account del fenomeno religioso nel dibattito nordamericano. Argumenta Journal Law, Jacarezinho - PR, Brasil, n. 29., 2018, p. 15-48. DOI: 10.17564/2316-3828.2018v7n1p13-24

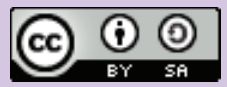

Este artigo é licenciado na modalidade acesso abertosob a Atribuição-Compartilhalgual CC BY-SA

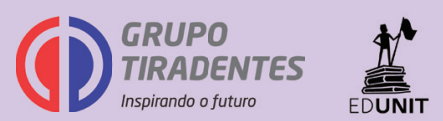

